\title{
La lengua salvada. Acerca de dibaxu de Juan Gelman ${ }^{1}$
}

\author{
por Enrique Foffani \\ (Universidad Nacional de La Plata - Universidad Nacional de Rosario)
}

\begin{abstract}
RESUMEN
Se intenta leer el libro dibaxu de Juan Gelman escrito en sefardí desde el horizonte de la tradición poética latinoamericana. A través de la metáfora acerca de "la lengua salvada" de Elías Canetti (una imagen-acontecimiento de su propia autobiografía) es posible reflexionar sobre la condición de judio y también sobre la relación de la lengua materna y la infancia. En la estela de Rubén Darío y de los poetas posteriores que se vieron en la situación de cambiar de lengua por diversos motivos, Juan Gelman elige el ladino o español sefardí como un doble extrañamiento de la lengua poética: por un lado pertenece a la línea azkenazí y no sefardita y por el otro recupera el español del siglo XV en consonancia con otras propuestas poéticas en las que había ya ensayado el rescate de la voz de poetas españoles como San Juan de la Cruz, Santa Teresa y los poetas místicos árabes. Desde esta perspectiva, el artículo analiza desde la extraterritorialización de la lengua poética los temas de dibaxu y otros libros anteriores a fin de señalar ciertas constantes y sus modos diferentes de articulación en el texto poético.
\end{abstract}

\author{
Me echaron del palacio/ \\ no me importó/ \\ me desterraron de mi tierra/ \\ caminé por la tierra/ \\ me deportaron de mi lengua/ \\ ella me acompañó/ \\ me apartaste de vos/ y \\ se me pegan los huesos/ \\ me abrasan llamas vivas/ \\ estoy expulsado de mí. \\ Juan Gelman, Com/posiciones
}

$\operatorname{dibaxu}^{2}$ sorprende al lector por el uso de una lengua extraña y familiar al mismo tiempo. En el "Escolio" de este libro, Gelman explica de este modo la experiencia de lo inusitado que lo empujó a su escritura: "Escribí los poemas de dibaxu en sefardí, de 1983 a 1985. Soy de origen judío, pero no sefardí, y supongo que eso es algo que tuvo que ver con el asunto". Eso — que, por otro lado, es el título de uno de sus libros- no puede ser del todo explicado, desplegado en un enunciado tan nítido que pueda dar cuenta de su certidumbre; eso habla de una experiencia que no puede escindirse de la lengua en la que se escribe. Elías Canetti, ese otro judío errante de la Europa del Este, denominó a su autobiografía "die gerettete Zunge", es decir, la lengua salvada. ${ }^{3}$ Es cierto que ambos escritores de familia judía escriben su obra en el exilio, ya que la errancia se vuelve instancia fundante de sus escrituras. En el caso del poeta argentino, forzado a abandonar el país, la errancia aparece en el texto bajo la insistencia por fijar en él la fecha de

\footnotetext{
${ }^{1}$ Este trabajo fue publicado en 1995 en Culturas del Río de la Plata (1973-1995) Transgresión e intercambio, Roland Spiller (editor), Frankfurt am Main, Vervuert Verlag, pp. 183-202.

${ }^{2}$ Gelman, Juan. dibaxu, Buenos Aires, Seix Barral (Biblioteca Breve), 1994.

${ }^{3}$ El libro de Elías Canetti Die Gerettete Zunge fue traducido al español por Lola Díaz con el título de La lengua absuelta. Preferimos, en cambio, "la lengua salvada", puesto que el alemán "retten" es salvar de un peligro, poner a salvo, guarecer ("bewahren") y, a pesar de que Gelman no se ha propuesto "salvar" del olvido una lengua a punto de desaparecer (que no era hablada tampoco por sus antepasados judíos, que no provenían de hecho de la rama sefardita) la lengua salvada implica sobre todo el trabajo de recuperación de la memoria.
} 
composición, en donde no solo quedan registrados los rastros del sujeto sino también los de la escritura. En Canetti, además de la errancia en el espacio, hay una errancia por las lenguas. Pero algo, pese a las diferencias, los une y no es únicamente el hecho de ser judíos sino el Ladino, ${ }^{4}$ la lengua materna de Canetti y la lengua que Gelman adopta para escribir dibaxu.

Frente a tantas lenguas a las que por distintas razones estuvo ligado, a saber: el Ladino, el rumano, el búlgaro, el inglés y el alemán, la errancia lingüística de Canetti lo vuelve, de algún modo, un escritor moderno, en el sentido de George Steiner, es decir, en un escritor que vine la paradoja de estar lingüísticamente "sin casa" y que, en su errar de lengua en lengua, la encuentra finalmente en el alemán. Die gerettete Zunge se abre con un relato que condensa la relación de la lengua con la memoria. Es, en verdad, una escena que se repite en la infancia del escritor que solo tiene dos anos. La escena, que representa "el recuerdo más remoto" (meine fruheste Erinnerung) es aquella que está más lejos del presente y que de hecho lo fundamenta, vale decir, coexiste con él. Es una escena que describe la amenaza de perder la lengua como órgano pero que, metafóricamente, puede leerse como la lengua en la que se habla. Al cuidado de una muchacha búlgara que mantiene una relación amorosa clandestina, todos los días el niño es víctima de la misma amenaza por parte del amante de la muchacha:

Mi recuerdo más remoto esta bañado de rojo. Salgo por una puerta en brazos de una muchacha, ante mí el suelo es rojo y a la izquierda una escalera igualmente roja. Frente a nosotros, a la misma altura, se abre una puerta y aparece un hombre sonriente que viene amigablemente hacia mí. Se me aproxima mucho, se detiene, y me dice: “¡Enseña la lengua!”. Yo saco la lengua, él palpa en su bolsillo, extrae una navaja, la abre $y$ acercando la cuchilla junto a mi lengua dice: "Ahora le cortaremos la lengua". No me atrevo a retirar la lengua, él se acerca cada vez más hasta rozarme con la hoja. En el último momento retira la navaja y dice: todavía no, mañana". Cierra la navaja y la guarda en su bolsillo.

En el pasado era una escena repetida $y$, a su vez, en cuanto recuerdo, es un pasado que se repite en el presente. Para un escritor, esa escena es como la metáfora de la amenaza que siempre pesa sobre él y que es, ciertamente, la del silencio forzoso: quedarse sin lengua, en los dos sentidos. De algún modo, Canetti se queda sin lengua, la lengua materna, adoptando más tarde el alemán, pero el valor de la escena que abre su autobiografía consiste menos en la infatigable repetición de la que es víctima el sujeto que recuerda, que en el hecho de haber salvado su lengua de la amenaza. Poner la lengua a salvo: la historia de una lengua es la historia de su rescate. El ladino es la lengua del pasado, es la lengua en la que habla su memoria, es en verdad el habla de la memoria - lo cual recuerda, de hecho, otra autobiografía, la del otro escritor errante, Vladimir Nabokov, titulada Speak Memory - y que, como Canetti escribe, "solo los acontecimientos especialmente dramáticos, muertes u homicidios, y los peores terrores, se me han grabado en ladino, $y$ de una manera exacta e indeleble." La experiencia primera, es decir, primitiva, es una inscripción, una suerte de impresión que retorna como lengua y en los dos sentidos: la impresión como lo imborrable y como lo amenazante. Si la primera habla de la memoria indeleble, la segunda no es sino esta experiencia que intimida e inquieta a la vez y que, grabada sobre aquélla, reaparece siempre en el presente del acto de recordar.

El uso que Gelman hace del ladino en dibaxu, al lado de su versión castellana actual, podría compararse al efecto de extrañamiento que provoca su incrustación en el texto alemán de Canetti. Si los recuerdos de la infancia se imprimen en el ladino y producen lo que él denomina la "traducción en el inconsciente", vale decir, una inscripción que se acuña en el presente, de un modo similar habría que pensar el valor de reminiscencia que adquiere el ladino de Gelman: en el discurso amoroso la palabra se vuelve la reliquia que el sujeto enamorado guarda celosamente para decir la ausencia que lo acosa.

\footnotetext{
${ }^{4}$ Remitimos para este aspecto el apéndice al final del trabajo.
} 
Si puede afirmarse una verdad sobre la poesía de Juan Gelman que pueda, a su vez, sostenerse en el acto de lectura, no sería otra que el trabajo de construcción de la lengua en su sentido más literal que es el de edificarla, el de corporizarla en el poema, el de levantar concretamente sus cimientos. Pero dicho así es casi no decir nada; qué poesía no estrecha con el lenguaje su razón de ser y estar en el espacio de la escritura? Se trata, más bien, en el caso de Gelman de una insistente e insoslayable voluntad por construir la lengua en la que escribe y a la que, a pesar de todo, permanece fiel. Hijo de inmigrantes ucranianos, su lengua de pertenencia es, sin embargo, la lengua española en su inflexión rioplatense, una lengua que no es la de su madre, aunque durante la infancia su hermano Boris le leyera poemas de Pushkin en ruso. Todo la producción poética de Gelman es el laborioso empeño de una gran fidelidad a su lengua, a lo que el español puede, a todo lo que es capaz de expresar aunque haya que contravenir las leyes de la gramática. Desde esta perspectiva, se construye la lengua en la mezcla y no en la pureza: no busca ser depurada de toda palabra extraña, es decir, extranjera, sino que opera por contaminación. En este sentido dibaxu hace emerger este trabajo de construcción de varias lenguas posibles y todas dentro de los límites - en los confines - del español, ya que el ladino es considerado grosso modo un dialecto del español. Entre otros muchos efectos, el ladino de dibaxu hace más legible el español de las "crónicas de Indias", el español de Santa Teresa, el español de San Juan de la Cruz, el español de los poetas sefarditas, ya que pone de manifiesto cierto recorrido "histórico" de la lengua. Pero no menos cierto es la ineludible constatación de que ésta se halla siempre sometida a la ley de la mezcla: el español de los místicos se enlaza con el del tango; el de las crónicas con un español actual; una lengua conversacional es atravesada por una lengua infantil que ignora las normas de la gramática. Por eso, la poesía de Gelman está escrita en una lengua que es, a la vez, la continua posibilidad de otras tantas que nacen y se mezclan en su propio seno. Una lengua nativa que actúa como si fuera una lengua materna: una matiz que engendra y ahíja todas esas lenguas y las hace en el espacio del poema.

dibaxu no es, en verdad, el último libro escrito por Gelman sino el último publicado. La demora de su aparición (fue compuesto casi una década atrás, más exactamente entre 1983 y 1985) contiene un gesto que no solamente señala hacia quien escribe y publica sino también hacia la escritura misma. Se desarticula el tiempo de la producción y el de la edición, distanciándolos, y en el lapso, hacen su aparición otras obras. De este modo, el conjunto de la producción trama un recorrido que la lectura con su propia actualidad vendría a rearticular de otro modo en relación a los libros anteriores. Había en dibaxu una no congruencia que altera el recorrido cronológico de la producción; no es consecutivo de Salarios del impío (1993) sino coetáneo, en cuanto a la producción, de Com/posiciones y Eso, editados también tardíamente en Interrupciones II (1988). En el mismo escolio a dibaxu Gelman piensa este libro como una "culminación" o "desemboque" de citas y Comentarios compuestos ambos en 1978 y 1979. De este modo, esta suerte de movimiento sísmico en la producción poética también alcanza al espacio de la escritura que elige el ladino y lo retraduce al castellano actual, como si fueran dos estados sincrónicos enfrentados, como si en ese cara a cara se tratara de registrar el pasado y el presente de una misma lengua, lo que fue contrapuesto a lo que es.

\section{II}

dibaxu no es tanto un libro extraño porque haya sido escrito en ladino, en el español sefardí, sino por la naturalidad con que el autor adopta una lengua más allá de los alcances ideológicos de la elección: ¿Gelman ladino en, al principio, dos de los sentidos de la palabra, vale decir, escritor del Ladino y también escritor ladino, el que habla con soltura otra lengua aparte de la propia?

Este desplazarse de una lengua a otra está más íntimamente ligado a la errancia del poeta y a su articulación en lo textual como la superficie donde pueden leerse las fechas como memorias y testimonios de un recorrido histórico doblemente orientado: hacia el de la Historia y hacia el de $s u$ historia personal. Tal vez el lugar mismo de la obra de Gelman sea este nudo en 
donde indefectiblemente convergen ambas instancias. Una obra en permanente construcción que, a su vez, se inscribe en la modernidad histórica, tal como la define George Steiner, originada en la profunda crisis de postguerra y que representa una revolución lingüística: una modernidad que hospeda y expulsa, al mismo tiempo, a todos aquellos escritores que parecen, como Nabokov, Kafka, Beckett, Borges, Joyce y tantos otros, haberse quedado lingüísticamente sin casa. ${ }^{5}$ Es indudable que la poesía — continúa el crítico- es el ejemplo esencial de la vida del lenguaje y que la máxima paradoja para el escritor moderno consista en su condición extraterritorial, la de ser y estar doblemente exiliado: exilio del territorio y de la lengua at mismo tiempo. Este pluralismo lingüístico o, como lo llama Steiner, carencia de hogar, señala, por un lado, "una relación de duda dialéctica" con respecto a varias lenguas y, sobre todo, con respecto a la lengua nativa y, por otro, pone de manifiesto la constitución de una literatura del exilio que representaría "el impulso principal" de esta modernidad. Beckett y Borges testimonian gestos extremos del desajuste que adquiere, en cada uno, un signo opuesto: el escritor irlandés extraterritorializando su lengua materna desde el afuera de otra lengua $y$ el escritor argentino desde el adentro mismo de la suya. El caso de Nabokov quizás sea el paradigma más radical del plurilingüismo moderno que complementa de un modo extraordinario su situación de escritor nómade. "Como él mismo señala con incansable y ofendida insistencia — escribe George Steiner-, la barbarie política del siglo lo convirtió en un exiliado (en vagabundo, en Hotelmensch) no solo con respecto a su tierra natal sino también con respecto a la lengua rusa." En este sentido puede leerse un paralelo entre el escritor ruso y Gelman no solo porque se vieron obligados asimismo al exilio político como tantos escritores que debieron abandonar sus respectivos países sino porque esta extraterritorialidad los llevó a centrar su obra en la nostalgia de la lengua propia.

$\mathrm{Si}$ el escritor ruso pasa de una lengua a otra, el argentino se aferra a la suya pero para hacerla estallar e, incluso, como en el libro que nos ocupa, apelar a un dialecto del español, el ladino, sobre el cual algunos lingüistas sostienen que se trata, en la actualidad, de una lengua en vías de desaparecer. Una pasión compartida acercaría aún vez más al autor de Lolita al poeta argentino desde la sospecha de que no solo el exilio es territorial sino también lingüístico y es la cuestión de la traducción o, incluso, del fenómeno de la retraducción: mientras Nabokov retraduce al ruso su Lolita escrita en inglés, Gelman elabora parte de su poética haciendo de la traducción su principio constructivo tal como ocurre con sus tres libros titulados Traducción I, II, III. ${ }^{7}$ De este modo, el exilio de Gelman también puede leerse como una construcción de su

\footnotetext{
${ }^{5}$ En su libro Extraterritorial. Ensayos sobre literatura y la revolución lingüística: leemos: "Los orígenes de la revolución lingüística coinciden desde el punto de vista del tiempo y de la sensibilidad con la crisis de los valores morales y formales que precede y sigue inmediatamente a la Primera Guerra Mundial... Lo que en otro lugar denominado "el apartarse de la palabra" y la derrota de las letras humanísticas ante la barbarie, corresponde estrictamente a la nueva lingüística, a los nuevos esfuerzos —filosóficos, psicológicos y poéticos - para establecer un centro semántico. Centrándose en "la profunda contradicción y fragilidad del lenguaje" Steiner relaciona los trabajos lingüísticos de Russell, de Wittgenstein y de los círculos de Moscú y Praga con la metáfora del silencio o del lenguaje fracasado en la literatura de Hofmannsthal y Kafka. (Barcelona, Barral, 1972, p. 90).

${ }^{6}$ George Steiner sostiene que a causa de su destierro de Fialta, "Nabokov se ha construido una casa de palabras. Para ser específicos, digamos que la situación multilingüe, interlingüística de Nabokov es tanto el tema como la forma de su obra (indudablemente estas dos cosas son inseparables y Pale Fire es la parábola de su fusión)". "No sería nada excéntrico leer la mayor parte de la obra de Nabokov —continúa el crítico- como si se tratara de una meditación (lírica, irónica, técnica, paródica) acerca del lenguaje humano, acerca de la enigmática coexistencia de diferentes visiones de mundo generadas lingüísticamente y de una profunda corriente que se encuentra en la base de multitud de lenguas y que en ciertos momentos oscuramente se une a ellas". (Ob. cit., p. 20.)

7 Se trata de los siguientes libros: Traducciones I. Los poemas de John Wendell (1965-1968), Traducciones II Los poemas de Yamanokuchi Ando (1968) y Traducciones III. Los poemas de Sident West (1968-1969). Miguel Dalmaroni en su libro Juan Gelman. Contra las fabulaciones del mundo plantea un acercamiento entre la noción de "traductor" que aparece en estos libros y la de "actor" brechtiano y escribe que Gelman presenta "estos poemas como traducidos de un idioma extranjero" [...]
} 
casa lingüística y no según la propuesta heideggeriana de la poesía como el ser del lenguaje sino también como el estar en el lenguaje: no únicamente una ontología, también un emplazamiento (que se vuelve desplazamiento), una ubicación (que se vuelve desubicación), vale decir, un espacio móvil, un territorio extraño que puede llamarse extranjero y que representa el mapa de su nomadismo y que podemos leer con total nitidez en bajo la lluvia ajena (notas al pie de una derrota):

Pero ninguna lengua oscura entonces me decía sepá, nienteafato, ferboten, nius, antunche. Eran idiomas de no estar.

Por lo tanto, no es simple precisar en qué consiste su fidelidad a la lengua, lo que significa para un poeta como Gelman estar dentro o fuera de ella, si se trata, en verdad, de un poeta que se sitúa también como extranjero en su propia lengua. En principio, creemos que dibaxu permite leer esta fidelidad a la lengua precisamente allí donde de algún modo se la traiciona: el Lugar del abandono y, al mismo tiempo, el de su reafirmación. Por un lado, como piensa Jorge Monteleone, el original y su retraducción es como un juego de espejos ${ }^{8}$ y, por el otro, es la tensión del mismo cuerpo de la lengua. Si, el cuerpo de la lengua en alta tensión: los poemas de dibaxu escriben la intensidad de una experiencia con una lengua casi muerta, como el ladino, y una versión correspondiente como el español actual. Acaso es la treta de un poeta ladino, pero esta vez en el tercero de sus significados, vale decir, el de un poeta taimado y sagaz cuya astucia intenta ocultar una suerte de bigamia, la que vive él con dos lenguas y que, tal como manifiesta en el "Escolio" a dibaxu, una es la original y otra es la lengua de traducción, la lengua actual?

III

Habría que leer la ardua ejercitación del poeta bígamo en la poesía latinoamericana al menos desde Rubén Darío, el bígamo joven, l'enfant terrible que le confiesa a su abuelo su infidelidad con la lengua francesa, la lengua querida y por lo tanto centro de su amor y deseo. ${ }^{9}$ Gelman, en cambio, se manifiesta más perspicaz y menos vehemente, es decir, más ladino, al pretender que la lengua de la traducción no sea una nueva lengua sino una lengua congénere que actualiza una mismidad olvidada pero pronta a reaparecer. Entonces, quiere decir que el papel que juega la lengua de la traducción contrarresta, de algún modo, ese efecto de extrañamiento del ladino, para que el sentido no se pierda y pueda ser recuperado a su dispersión? Ciertamente no, porque el extrañamiento, esa experiencia freudiana que se vuelve, de pronto, um-heimlich, vale decir, lo que desfamiliariza hasta volverse extraño (y que, en Gelman, se liga siempre por su condición de eterno exiliado a lo extranjero) es el cuerpo mismo de las palabras, los significantes, que muestran precisamente sus parecidos.

Si el ladino representa la lengua querida como lo era el francés para Darío, a diferencia de éste, Gelman encuentra en una lengua arcaica y no en la lengua de la modernidad por antonomasia, al menos desde Baudelaire, la intensidad necesaria para decir su pasión. Si se

“este distanciamiento del contexto —una utopía en el sentido primario del término- debilita, si no disuelve, la ilusión realista de su poética inicial” (Buenos Aires, Almagesto, Colección Perfiles, 1993, p. 61.)

${ }^{8}$ Se trata de la excelente reseña del libro que escribió Jorge Monteleone para la agencia de información TELAM en la que leemos: "Hay en dibaxu un modo de establecer relaciones sonoras, léxicas y metafóricas en el poema, percibidas como efecto de superficie: el sentido se potencia en la cadena verbal, en sus juegos de ecos, en sus espejos". Y más adelante escribe: "los poemas no están estrictamente en uno y otro lado de la página (en sefardí o en castellano) sino en esa zona suspendida, intermedia en el fluir de tiempos que puede reunirse en la conciencia del poeta $y$ la del lector".

9 Transcribimos la cita textual de "Palabras liminares" de Prosas Profanas y otros poemas (1896-1901): "Luego, al despedirme: "-Abuelo, preciso es decíroslo: mi esposa es de mi tierra; mi querida, de Paris" en: Poesía (1), Biblioteca Ayacucho, Hyspamérica, impreso en Buenos Aires, 1986. Edición de Ernesto Melia Sánchez y prólogo de Ángel Rama, p. 180. 
trata, entonces, de una poética de la pasión de y por la lengua parecería, en principio, un contrasentido, recurrir para ello a una lengua en trance de extinción. ${ }^{10}$ No es tanto el viaje a las raíces o el lugar original de la lengua como el hacer todo lo posible para re-sucitarla: de allí que la nostalgia atraviese toda la producción poética de Gelman y configure no solamente un tema que lo vincula a su propia condición de exiliado, sino también una experiencia con la lengua como otro territorio que lo refugia y, también, lo destierra. ${ }^{11}$ La nostalgia de una lengua muerta y el esfuerzo por volver a decir "en voz alta", lo cual significa, volverla a pronunciar, podría ser la cartografía de la pasión, el recorrido erótico de la lengua, pues el mismo autor anota que dibaxu "quizás [...] sea una reflexión sobre el lenguaje desde su lugar más calcinado, la poesía". Por lo tanto, la pasión que se suscita en este libro y se consume en dos elementos (Eros y la lengua) resucita las "relaciones vitales" entre ambas instancias. ${ }^{12}$

Este poeta ladino, en dos de sus sentidos, a saber: el poeta bilingüe y el taimado, el lenguaraz y el astuto, sitúa en el lugar de la poesía el lugar de su pasión, vuelta entonces también ladinamente doble: no solo lo que ella representa para el poeta como objeto de amor sino también como lenguaje, como discurso. De allí la insistencia en su escritura poética posterior a dibaxu de la imagen "calcinada", es decir, de la imagen barrocamente "ardida" para cuenta de la pasión en el sentido señalado. ${ }^{13}$

\section{IV}

${ }^{10}$ El reconocido romanista Marius Sala plantea, en su libro Estudios sobre el judeoespañol de Bucarest, (México, Universidad Nacional Autónoma de México, 1970), tres modos distintos de desaparición de la lengua: (a) por calamidad o exterminio; (b) por transformación — como es el caso del Latín—; (c) por abandono para optar otra lengua. "Esta última modalidad, bastante frecuente, es la que queremos estudiar aquí, al proponernos estudiar la muerte del idioma judeoespañol". La distinción que el lingüista rumano hace del ladino como forma escrita y literaria, por un lado, y por otro, como lengua corriente, como umgangssprache, resulta bastante productiva, en vistas de nuestro trabajo, puesto que el ladino, desde un enfoque estrictamente histórico se encuentra en intima relación con el español de su tiempo. Esta contemporaneidad señala las relaciones de filiación dialectal entre el castellano y el ladino. En este libro leemos: "La forma escrita del judeoespañol de los siglos XV y XVI difería muy poco del español literario utilizado en España en la misma época." El lingüista rumano cita a su vez a Gonzalo de Illescas, un viajero español que 50 años después de la expulsión, a los judíos emigrados en Oriente y escribe: "Los israelitas se llevaron de España nuestra lengua, todavía la conservan y la usan de buena manera. Y además es seguro que en Salónica, Constantinopla, El Cairo, Venecia y otras ciudades comerciantes, solo compran, venden y hacen negocios en español. Y he conocido en Venecia a muchos judíos de Salónica, que, aunque eran muy jóvenes, hablaban el castellano tan bien como yo."

${ }^{11}$ El destierro no es solamente un tema crucial en la polémica gelmaniana sino que también se orienta hacia la doble instancia que consiste en esa particular situación de estar fuera de lugar y de la lengua propia. En este sentido, el libro bajo la lluvia ajena (notas a pie de una derrota) escrito en Roma en mayo de 1980 establece con dibaxu una serie de relaciones muy significativas: en primer lugar, ambos títulos en minúscula remiten a una situación especial abajo la cual metaforiza la situación del exilio como una experiencia de "otredad": bajo la lluvia ajena, el lugar de los otros, vale decir el otro como el no-yo; en segundo lugar, ambos son libros que hablan del amor y de hecho todos los poemas están fechados y escritos en ROMA, que es anagrama de "amor"; en tercer lugar, puede leerse tanto en uno como en otro lo que hemos denominado la experiencia de extraterritorialización lingüística: "Será soledad, que no tiene discursos?" O: "En que lengua podría hablar la soledad?" (De bajo una lluvia ajena, p. 22; en: Interrupciones II, Buenos Aires, Tierra Firme, 1988.)

12 George Steiner plantea este tema en su obra ya citada Extraterritorialidad. Transcribimos textualmente la cita: "Resulta absurdo lo poco que sabemos acerca de las relaciones vitales entre Eros y el lenguaje. El bilingüismo de Oscar Wilde podría ser la representación expresiva de una dualidad sexual, el símbolo lingüístico de los nuevos derechos de experimentación e inestabilidad que Wilde exigía para la vida del artista. Tanto aquí como en otros puntos importantes, Wilde es una de las verdaderas fuentes del espíritu moderno." (p. 17)

${ }^{13}$ En salarios del impío continua y ahonda esta imagen, vinculada ahora, a la palabra que se consume para nombrar lo innombrable: "lo que fue cuerpo y se calcina para que empiece el horizonte" y también, a una experiencia de la nada: "brasa extremada, como calcinado, entrega del no ser". 
Si Darío funda su condición de poeta bígamo con una amante — con su querida francesa- que, en la transacción amorosa, le ofrece el beneficio de volver moderna a la poesía, Gelman rompe la prestigiosa tradición francesa para buscar "otra" lengua y con ella ya no una dimensión actual sino, por el contrario, una dimensión pretérita. Mientras a Darío lo que le fascina de la lengua francesa es lo novedoso porque le permite componer una nueva música (Ángel Rama habla de la apropiación por parte del poeta nicaragüense de todo el instrumental contemporáneo tanto lingüístico como poético) lo que opera en Gelman como fascinación es hallar la veta arcaica de una lengua casi muerta para hacerla resu(s)citar, es decir, volver a hacerla sonar en el esplendor de su nostalgia.

Pero, más allá de la distancia entre Darío y Gelman respecto a la apropiación de lenguas que difieren fundamentalmente en cuanto a su valor temporal, no menos evidente seria la cuestión de que ambos se acercan al dejar de ser poetas exclusivamente castos, exclusivamente castizos. Esta sería la manera de definir al poeta bígamo como aquel que pierde la castidad conyugal llamada casticidad y se aventura en la experiencia de extrañamiento lingüístico de apropiarse "otra" lengua sin abandonar la propia. Por eso, el use del casticismo que ambos poetas practican no puede leerse exento del profundo ejercicio amatorio que los vuelve poetas y que es, de algún modo, reescribir, hipotéticamente, gran parte del acerbo de la poesía española. Pero, además, el casticismo es la marca en el cuerpo de la escritura poética, un cuerpo por definición heterogéneo, que habla no solamente de un erotismo sino también de una política: no es posible el casticismo sino bajo el control de quien se propone crear una lengua poética pero sin someterse al vasallaje de "otra" cultura. Precisamente ése es el mérito de Darío: producir una lengua poética desde la autonomía de todo acceso "official" de la cultura: "Nuestro modernismo nos va dando -escribe el poeta nicaragüense en España Contemporánea - un mundo aparte, independiente de la literatura castellana." (el subrayado es nuestro). Pero tal proyecto presenta en Darío, por su fuerte articulación fundacional, un complejo proceso de apropiación lingüística y cultural que Ángel Rama denomina "operación revalorizadora magistral" y que se refiere a la lectura voraz de varios siglos de poesía española en el Repositorio de la Rivadeneyra. De hecho, Gelman se inscribe en esta tradición latinoamericana de poeta que necesariamente lee el pasado poético para más tarde escribir primero el ejercicio de imitación y después escribir en contra de ese repertorio de lecturas. Tal es el caso de Darío y Martí en el siglo XIX y Vallejo y Borges en las primeras décadas de este siglo. Son los poetas fuertes que encuentran la energía de su escritura en la voracidad de la lectura, son los poetas lectores o los lectores que se vuelven poetas.

V

Como el Darío que compone su Parnaso poético casi con la desmesura del Funes borgiano, es decir, mediante un ejercicio perfecto de la totalidad de la poesía (al menos, de "toda" la poesía escrita en castellano), como el primer Vallejo antes de empezar su obra poética escribe una tesis sobre la poesía romántica y también como el Borges poeta, no el del fervor primero que lo alejaba de las formas tradicionales, sino el del poeta ciego que encuentra en la estructura clásica el ritmo versal; así también en Gelman es posible leer estos "ejercicios espirituales" con el verso de la tradición aunque en él ya no se cumpla con la penitencia de la imitatio de ritmos y metros. Más bien se trata de imitar un estilo y no del todo fidedignamente, de reescribir un trozo o fragmento que pueda reconstituir la atmósfera del original y de ninguna manera de forma definitiva, de producir una textura que sea capaz menos de referir que de suscitar otro texto al que se le obliga a coexistir junto a otros que se presentan tan disímiles como alejados entre sí (una convivencia inaudita pero audible en el cuerpo del poema que se vuelve, de ese modo, en el espacio de una utopia); se trata, entonces, tal como Rama había pensado de la empresa de Darío, de una "operación revalorizadora" pero cuyo efecto "magistral" ya no es la consecución de una pericia técnica. Lo que Gelman ejercita es la maestría para poner en relación "citas" y "comentarios" no de textos completos sino tan solo de partes de esos textos.

El poema deviene, en consecuencia, casa de citas, donde San Juan de la Cruz dialoga 
con Pascual Contursi, el rey David con Cátulo Castillo, Isaías con González Castillo, Ezequiel con Le Pera, Homero Manzi con San Pablo. Queda construido un lugar utópico, una zona de lo imposible que precisamente la lengua en su juego diferencial hace posible. En este sentido, si la lengua cita y comenta, traduce y parlotea, imposta su voz y reproduce como un imitador de voces, no hay otro camino que el de la contaminación que impone el gesto de la herejía. San Juan de la Cruz y Pascual Contursi bien podrían ser el ejemplo: el lenguaje de la mística y el lenguaje de esa otra mística de la melancolía llamada tango. Un lenguaje que se sitúa entre el misterio que no puede ser dicho, la experiencia que el verbo no puede registrar ("Entréme donde no supe/ y quédeme no sabiendo") y la experiencia que se dice y pronuncia gracias a la pérdida, vuelta motor e ímpetu que provocan la palabra. Como una suerte de inversión, el tango se hace místico y la mística tanguera, vale decir, hay "una noche oscura del alma" en mi noche triste de Contursi y una ausencia de la amada que produce un abandono imperdonable ("porque su luz no ha querido/mi noche triste alumbrar") en la poesía mística de San Juan.

En el "Escolio" Gelman escribió que dibaxu es "La culminación o más bien el desemboque de citas y Comentarios, dos libros que escribí en pleno exilio [...] como si la soledad extrema del exilio me empujara a buscar raíces en la lengua, las más profundas y exiliadas de la lengua." Si el exilio es una experiencia extrema y, de algún modo, radical para el sujeto que escribe, a tal punto que resulta él mismo exiliado de sí y no solo de su lengua, puesto que ya no le es posible siquiera el sosiego de la explicación, dibaxu es esa culminación extraterritorial, vale decir, puesta fuera del territorio geográfico y lingüístico, una culminación sui géneris que ya no se eleva sino que, por el contrario, se hunde, se ahonda, se deja caer hacia baxu. Una experiencia de "desembocadura" para un sujeto que se vuelve boca para hablar de amor en una lengua que no es la suya.

VI

Lo que sorprende del poeta ladino - el poeta lenguaraz - es la familiaridad con la lengua que adopta. Pero esta experiencia extraterritorial, plenamente moderna en el sentido de Steiner, combate la figura romántica del escritor enraciné, del genio vernáculo que se siente llamado a construir una nación precisamente a partir de la interpretación ideológica del pasado. No se trata ya del poeta-vate, el poeta elegido que hace posible con su canto el advenimiento de la Nación y del que Leopoldo Lugones, en el contexto de la poesía argentina, es el mejor ejemplo sino, por el contrario, de un poeta sin nación, de un poeta que parece vivir su patria, al menos desde el momento del exilio a la actualidad, bajo estas condiciones de estar afuera y que, incluso en dibaxu, pierde el último territorio de pertenencia que es su lengua propia. En este sentido, ésta se radicaliza en dibaxu hasta su extraterritorialización pero, a la vez, no menos significativo que ésta decisión extrema resulta todo el trabajo que con y contra ella ha venido realizando. Por eso, la nostalgia más que responder a las leyes del constructivismo temático, medularmente articulado a las condiciones mismas de producción, representa la nostalgia por la lengua nativa de la cual también se siente expropiado.

Habría que pensar, por lo tanto, que la poesía de Gelman, despojada de toda mística nacionalista y de toda encarnación genial, no busca echar raíces en el idioma nacional, vía de acceso directo y obligado a la asunción de la identidad ( y ya sabemos que hablar de identidad nacional implica el emergente residual y extraño, siempre extranjero y que, bajo la lógica del dispositivo, resulta ser el "otro" contra el que aquella necesariamente se recorta), sino echar raíces en una lengua propia para encontrar en ella, en su uso o en su desuso, la resonancia de una nueva intensidad, una invención, una inflexión inusitada. En verdad, no hay lengua propia, el uso es lo propio de la lengua, lo que hace posible su existencia a expensas de ella misma; dicho de otro modo: se trata, en definitiva, de esa peculiar relación que el poeta establece con su lengua.

La infidelidad, el rotundo abandono de que es objeto la lengua propia, no hace más que reafirmarla en la nostalgia de su pérdida. Una vez más es posible decir que dibaxu y, con este libro gran parte de la producción poética gelmaniana, se construye a partir de las relaciones vitales entre Eros y la lengua. De un lado, la relación erótica entre sujeto y lenguaje y del otro, 
su relación política. Lo que vincula ambas instancias es la posición del sujeto al margen, fuera de los centros oficiales del poder - como es el caso de Gelman forzado a abandonar el país durante la última dictadura militar en Argentina-, lejos del territorio, un lugar lateral que el libro que tratamos sitúa abajo. Sin embargo, no todo es extraterritorial: se entiende que Gelman extraterritorializa su lengua dentro de la suya." propia, adoptando y cobijándose en una lengua que le es congénere. Es, de algún modo, ese trabajo con la lengua desde adentro y que Deleuze/Guattari llaman una literatura menor. ${ }^{14}$ Es este uso menor - tal vez habría que denominar "minúsculo" a juzgar por la insistencia con que Gelman utiliza las minúsculas en su poesía, incluso en el título del libro que nos atañe- el que entra en relación con la lengua propia: de ahí que el poeta hable con la lengua del niño y contravenga las leyes de la gramática. Por eso dibaxu entronca con todo lo que se relaciona en la poesía gelmaniana, con la lengua materna a la que pertenece y a la que abandona y que, siguiendo la metáfora de la raíz que aparece en el "Escolio", podríamos afirmar que es la lengua que arraiga pero también erradica.

VII

Las dos lenguas de dibaxu, el ladino y el castellano actual, se reparten en el libro el espacio de las páginas. Por eso el vinculo entre ambas podría llevarnos a pensar que el parentesco no reside en la supremacía del castellano como lengua "oficial" sobre el dialecto sefardi, puesto que sabemos que el idioma oficial es la extensión de un habla regional por sobre un territorio político. El efecto que las sigue, de hecho, vinculando es, paradójicamente, el parecido de las palabras, la semejanza que subsiste en la diferencia, como si una antigua y rancia familiaridad se volviera extraña a los ojos o los oídos del lector, una figura que reencuentra su importancia según puede inferirse de la palabra auctorial del "Escolio", la cual recomienda la lectura "en voz alta" de los poemas del libro. Su disposición enfrentada a la manera de las ediciones bilingües corrobora, por un lado, el valor de traducibilidad que le es adjudicado al castellano actual pero, por otro, es en el distanciamiento producido entre una y otra lengua que el lector comienza a percibir el espesor histórico, el paso del tiempo.

La paradoja que representa elegir una lengua en trance de morir para hablar de lo que está vivo se vuelve metáfora del acto amoroso: el destino de Eros, ligado siempre a Thánatos y a la imagen clásica del fuego que arde, podría definir el barroco gelmaniano pero ya no como la desembocadura de Eros Thánatos sino como el movimiento opuesto, un juego de inversión que transforma el amor en utopía, lugar del puro goce y que solo el discurso poético como el "lugar más calcinado del lenguaje" puede sacarle a aquél algún — aunque efímero - provecho de su naturaleza "indecible" o lo que los místicos nombraban "como lo "inefable". Por eso el amor es discurso, vestidura del sentido, retórica del deseo, hablar de lo indecible con una lengua que está desde el principio muerta para el sujeto que ama:

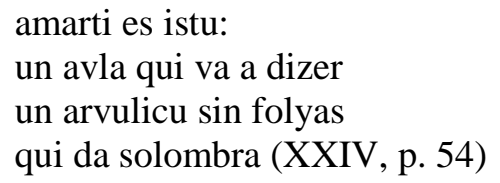

La lengua muerta del discurso erótico es esa palabra que está por decir y no dice, pura imposibilidad pero, también, invirtiendo un recorrido conocido, se puede leer su utopía o su

\footnotetext{
${ }^{14}$ Se trata del libro Kafka. Por una literatura menor, México, Era, 1978. En nuestro trabajo hemos tenido en cuenta del libro mencionado la noción de "literatura menor", es decir, no la literatura de una lengua menor sino la de una minoría hecha dentro de los limites de una lengua mayor. Así es como, sucedáneo a la elección del alemán en Praga por parte de Kafka, la lengua sefardita en el uso de Gelman (habría que pensar que su elección es hacer uso de una lengua en desuso, pensando que es "una lengua en peligro de desaparecer") implica la pérdida de la lengua propia, aunque ésta aparezca ya no como lengua original sino como una lengua de traducción. De este modo, Gelman parece "ladinar" su Ladino con la lengua propia, lo que él mismo denomina "castellano actual".
} 
consuelo: lo indecible resguarda y protege al menos un instante en la experiencia amorosa. Es la utopía de la consolación ya que sabemos muy bien hasta qué punto el amante es siempre un sujeto inconsolable:

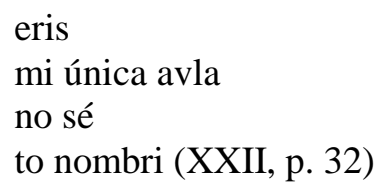

\section{VIII}

Dos libros de Gelman, uno anterior a la composición de dibaxu, Carta abierta (ParisRoma, enero de 1980) y otro posterior, Carta a mi madre (1989), pueden considerarse como libros que dialogan con aquél de un modo especial: ante el acto de desterritorialización de dibaxu, los dos libros mencionados lo reterritorializan. Son dos libros epistolares que ponen de manifiesto la posición de parentesco del sujeto lírico: la primera, Carta abierta, es la carta de Gelman escrita desde el exilio a su hijo, desaparecido junto a su esposa durante la última dictadura militar, es decir, es la carta del padre, y Carta a mi madre, también escrita en el exilio ante la noticia de la muerte de ésta, es la carta del hijo. La función de la carta como estructura de un libro de poesía sobrepasa el vinculo familiar del sujeto una vez "padre" y otra vez "hijo". Pero si la muerte de la madre o del hijo, provocan la escritura, operando como destinatarios de una carta cuyo destinatario está ausente en lo real, no menos significativa seria la relación afectiva, la dimensión erótica de la carta. Pero el erotismo de estos libros no se juega solamente en las relaciones de parentesco sin o también en las relaciones que el sujeto establece con la lengua en la que escribe. Carta a mi madre es también una reflexión sobre la lengua materna y Carta abierta la tentativa por feminizar la lengua de un sujeto padre y así investirla de una dimensión materna. En ambos libros —en ambas cartas- se produce un proceso de "aminoración": el sujeto hijo queda des-madrado ("aullabas cuando te separé de mi") y el sujeto padre despadrado (¿me despadrás para despadecerme?”) y en ambos casos es en el territorio exclusivo de la lengua que el sujeto habla, el lugar de la disminución, de una experiencia extrema que convierte a aquél en un ser menor que solo puede hablar como un el padre se hace hijo de su hijo ("deshijándote mucho") y el hijo madre de su madre ("todavía recojo azucenas que habrás dejado aquí/ para que mire el doble rostro de tu amor/ mecer tu cuna/ lavar tus pañales/ para que no me dejes nunca más.") En este sentido, el trabajo de aniñamiento que la poesía de Gelman realiza en el seno mismo del lenguaje (además de su articulación simbólica de la equivalencia poeta/ niño) es un trabajo contra la lengua, contra la gramática como reglamento y artificio. Desde ese lugar menor se le exige a la lengua lo imposible y aquí se concentra el poder político de su deseo: qué otra cosa seria amar la lengua si no es para pedirle una nueva intensidad, el hallazgo de un "avla" que no haya sido dicha todavía? Por eso es un síntoma que en dibaxu, donde este trabajo contra la lengua se hace radical, el tema dominante sea lo amoroso; "dibaxu" señala un lugar, una posición, un modo de situar el cuerpo del sujeto pero también es la metáfora espacial de la lengua:

$$
\begin{aligned}
& \text { dibaxu dil cantu sta la boz } \\
& \text { dibaxu di la boz sta la folya } \\
& \text { qu'il árvuli dexara } \\
& \text { cayer di mi boca (II, p. 11) }
\end{aligned}
$$

Desterritorializado de la lengua nativa, el ladino se vuelve la posibilidad de metaforizar una lengua sometida a un continuo e infinito movimiento de ahondamiento.

En las figuras de parentesco "padre" e "hijo" — una genealogía que invierte los roles específicos en una dialéctica amorosa- dibaxu delinea la del "sujeto enamorado": un sujeto que también desde el exilio trabaja contra la lengua y que termina, en verdad, exiliándolo. 
Desde el recorrido de la escritura poética, dibaxu se sitúa lo más abajo posible: entre la pérdida del hijo y la de la madre, la pérdida de la lengua propia. En Carta abierta el lenguaje se feminiza para convertir al padre en la padre, la hábil treta para socavar toda posible autoridad, para no volver a instaurar la Ley y exiliar una vez más al hijo del cuerpo materno. Por eso la padre no es una traición a la gramática sino la posibilidad de que la palabra se vuelva matriz, lugar de refugio para un sujeto desarraigado que busca, en definitiva, un asilo en la palabra. Desde esta perspectiva, Carta a mi madre lo explica con total nitidez:

\section{¿por eso escribo versos? ¿para volver al vientre} donde toda palabra va a nacer?

Si en la carta al hijo el padre se vuelve la padre, en la carta a la madre se ahonda aun más la reflexión sobre la lengua materna y su distanciamiento nunca definitivo: "pero esas maravillas donde me hijaste/ y to amadré/ to cercana distancia". De modo alguno, aunque estén bordeadas por la barbarie, estas cartas son cartas de amor, tal como podría leerse, también dibaxu, ya que tratándose, como es el caso, de la pasión amorosa, hay siempre una distancia que el sujeto que ama no puede salvar a menos que la lengua - fuera de su territorio, en su lugar de "abajo", extrañada de si, vuelta pura otredad — sea el Lugar de lo imposible.

IX

La apuesta de dibaxu es, evidentemente, una apuesta política. Escribir desde afuera $-\mathrm{y}$ afuera en los dos sentidos: en el exilio del cuerpo pero también en el de la lengua- confirma al sujeto, por un lado, como el expatriado, el continuo emigrante que se vuelve un "expulsado de si" pero también, en esa experiencia limite y desde ese lugar totalmente lateral todo enunciado se hace político, sobre todo, como plantea Deleuze, porque ese deslizamiento hacia el margen - que Gelman sitúa precisamente "abajo"- liga al individuo en una enunciación colectiva, vale decir que la escritura se solidariza con la comunidad y se hace revolucionaria. Así, en esa dialéctica de lo menor y lo mayor, como Kafka opta por el alemán de Praga para abandonar el checo, es posible leer el Ladino como la elección de un más allá de la lengua propia. El ladino, más que ratificar su condición de judío, lo transforma en el nómade de su lengua y le confiere, además, el espesor histórico que lo sella para siempre como una lengua de expulsados por decreto, una lengua obligada a salir de su lugar, a extraterritorializarse. De hecho, el Ladino, paradójicamente, funciona como la metáfora de la lengua castellana para el escritor latinoamericano, una lengua, como afirma Eduardo Grüner, "ya siempre desterrada, en exilio ${ }^{15}$ que hace estallar su tan mentada (mentida) unidad lingüística latinoamericana.

Como contrapartida de esta inten(s)ión política - la posibilidad de tensar la intención, es decir, dejar que la lengua hable más allá de sí- el amor a la lengua materna, como ya lo planteamos, aparece con más fuerza allí donde se la abandona: la dialéctica de la "cercana distancia", metáfora a su vez de la relación erótica. En ese punto, "abajo" reúne la dimensión intransferible y erótica de la lengua con la política: no escribir en la lengua oficial del Estado sino contra ella, poner al Padre fuera de la Ley autoritaria y buscarle un lugar materno en la palabra. Que Gelman escriba un libro de temática amorosa en medio de la barbarie que lo expulsa, es un acto de amor y, al mismo tiempo, político: se sabe, la revolución la hacen los que están abajo. Y, también, remontarse a las napas más profundas de la lengua, ir hacia ese

\footnotetext{
${ }^{15} \mathrm{El}$ artículo se llama "La Argentina como pentimento" (Sitio n ${ }^{\circ}$ 3, Bs. As., 1988, pp. 71-83) y junto con los textos de Steiner y Deleuze lo consideramos fundamental para la concreción de nuestro trabajo. La cita completa es: “....aquella intuición de Faulkner según la cual lo que mueve al escritor es la pasión siempre desmedida — excesiva, diría la modernidad bataillana - por crear algo que, precisamente, no existía antes de ese momento. Si algo de esa naturaleza ha logrado la literatura latinoamericana (y desde luego no me refiero al prefabricado "boom" de los últimos veinte años) quizá no sea sino porque, desde el vamos, eso que habla de los escritores latinoamericanos es un lengua ya siempre "desterrada", "extraterritorial" o en "exilio". (p. 73)
} 
lugar a buscar una lengua significa que, por otro lado, es imposible decir - todo decir se hace necesariamente precario-y por otro, por más abajo que se vaya, una lengua no deja nunca de decir.

\section{Apéndice}

En el "Escolio" de dibaxu Gelman afirma haber escrito los poemas "en sefardi" y agrega que su origen judío no es sefardita aunque adopte su lengua. Como sabemos, Gelman es hijo de inmigrantes ucranianos y su lengua nativa es el castellano rioplatense y no la lengua rusa, la lengua de su madre. Este primer deslizamiento de una lengua materna a una lengua nativa es un fenómeno importante que tiene repercusiones en su escritura poética, lugar donde resuenan muchas otras lenguas: la de Santa Teresa, la de San Juan de la Cruz, la de los místicos sefaraditas, las de las crónicas, la lengua del tango, la lengua infantil, etc. Pero la apuesta de dibaxu, al adoptar una lengua que él no habla y que tampoco pertenece a su horizonte culturalfamiliar de entronque judío, es una extraterritorialización lingüística tal como lo plantea George Steiner. Lo que resulta interesante seguir indagando es lo que en este trabajo decidimos llamar la intención, es decir, la intensidad de su propuesta, el hecho de buscarle a la lengua elegida una resonancia, una melodía, una manera de expresarse y que, obviamente, no puede dejar de relacionarse con la elección misma del ladino o sefardí. Al contrario que Gelman, hemos elegido el término "ladino" para referirnos al dialecto judeoespañol. Esta decisión no debe entenderse de ninguna manera como una "corrección" a la propuesta de Gelman sino como dos razones que están íntimamente ligadas a la construcción particular de nuestra lectura. Una es la que subyace al aspecto histórico de la lengua en cuestión: el ladino como denominación del judeoespañol traducido de la biblia hebrea y, después de la expulsión de la península, como la denominación de la lengua "expulsada" o "fuera del lugar natural". La segunda razón nos hace preferir el término ladino por las resonancias semánticas que provoca en nuestra lengua y que intentamos leer en la propuesta gelmaniana.

Antes de explicar, entonces, el motivo por el cual nos inclinamos hacia el término ladino es necesario aclarar el equívoco que existe con el término sefaradí y que Iacob $\mathrm{M}$. Hassán expone con total precisión: "si en hebreo sefardí significa "español" y alude por igual a los judíos hispanos de antes o de después de la expulsión, y aún —en ambientes israelíespuede englobar todo lo no - asquenazí; si en otras lenguas occidentales por influencia hebraica designa lo hispano- judío medieval, de lo cual lo "sefardî" seria solo prolongación o apéndice; si en español, en fin, lo sefardí - o sefardita - suele identificarse en la lengua corriente con lo "judío español" o incluso llega a ser sinónimo de "judío", alcanzando esta confusión unos niveles en los que sería exigible mayor precisión, lo cierto es que como término técnico lo sefardí queda reservado para lo judío-español diaspórico, con exclusión de su precedente hispano-judío medieval “. (En: "Introducción” a Actas del Primer Simposio de estudios Sefardíes, Instituto "Arias Motao “, Madrid, 1970, p. XVIII). Hassán señala, además en este mismo volumen el aspecto "escrito" de lo que él llama el "prejudeo español", vale decir, la lengua de los sefarditas antes de la expulsión - lo cual abarcaría un lapso de siglo- a través de la expresión "las traducciones ladinadas de la Biblia". Este aspecto está documentado, como ya lo dejamos aclarado en otra nota de este mismo trabajo, en el libro de Marius Salas, Estudios sobre el judeo español de Bucarest, (México, Universidad Nacional Autónoma de México, 1970, p. 14.) : "Al establecerse en el Imperio Otomano, los sefaraditas traían consigo las dos formas del español que habían hablado en España: la forma escrita, literaria, llamada "ladino", y el lenguaje corriente y cotidiano". En esta misma dirección, es fundamental para nuestro análisis una cita de I.S. Révah perteneciente a su artículo "Hispanisme et judaisme des langues parlées et écrites par les sefardim" (en el mismo volumen del Primer Simposio ya citado) y que transcribimos textualmente: "Durant le Moyen Age, les Sefardim, comme leurs compatriotes chrétiens, devaient donner a leur langue commune les noms divers de romance, lengua vulgar, castellano, español, etc. Après, l'expulsion, Moise Almosnino, de Salonique, appelle sa langue romance en 1564 et, à Constantinople, à la fin du XVI siècle, un traducteur 
déclare ecreri en romance español. Cependant, il est certain que les Sefarim médiévaux, surtout lorsqu'ils oppossaient leur langue vivante a l'hébreu, devaient, comme les Musulmans hispaniques, la désigner du nom de ladino. L'opposition entre le laso ba-kodes et le ladino était analogue a celle que la "Chronique d'Alphonse X" (vers 1340) établit entre des "cartas escritas una en arábigo e otra en ladino". Du XVI au XX siècle, c"est ce nom de ladino qui apparait les plus souvent dans los impressions réalisées dans l'Empire ottoman par les descendants des Juifs expulsés d'Espagne". (p. 233).

De este modo, elegimos ladino porque apela tanto a la lengua "viva" como a la lengua escrita de antes y después de la expulsión aunque, tal como es Lugar común, se convenga en llamar con el término de ladino a la lengua de los sefaraditas después de su expulsión peninsular, instalados en Portugal, Norte de África, Francia, la zona balcánica, etc. Si bien el ladino de Gelman remite a la lengua familiar, es decir, la langue vivante que intenta reconstruir su propia oralidad (que el texto tematiza y el "Escolio" recomienda con la palabra auctorial de leer "en voz alta"), también el ladino precisamente por su tradición medieval de traducir la lengua bíblica - la lengua de los libros - no deja de lado lo que es fundamental en la apuesta gelmaniana de dibaxu y por otro lado obvio: su dimensión escrituraria. Así, podría leerse este libro de Gelman que habla del amor como el amor a la lengua que se traduce. Tal como afirma Baruh Uziel: "Ladinar ande nosotros es solo hacer la traducción española de la biblia". Y ya sabemos hasta qué punto la traducción funciona como un principio constructivo en la poética gelmaniana. En esta perspectiva, la norma de traductibilidad se abisma aun más: ladinar su ladino para Gelman significa traducirlo al castellano actual, tal como él mismo lo dice en el "Escolio" "Acompaño los textos en castellano actual no por desconfianza en la inteligencia del lector.") Y para terminar con este apéndice quisiéramos transcribir otra cita en ladino de Baruh Uziel: "Ansi aribamos a la linia fondamental que caracteriza el ladino. Mirando el español como su propia lingua y alongados de cualunque centro español, los sefaradim desveloparon sus español a sus manera y envistieron en él creación judía. Los sefaradim fuemos dunque el Robinson Crosoe español, que topándose asolado, creó con sus manos los atuendos y los útiles por sostener sus español “ (p. 322; en: Actas dell Simposio de Estudios Sefaradíes, op. cit.). Esta es, nos parece, la dinámica del ladino como lengua: por un lado, una lengua que resiste la pérdida de lugar, la expropiación física del territorio que incluye, además, la pérdida de sus contactos lingüísticos y que desde el exilio se transforma en una resistencia robinsoniana y por otro, su contracara, su condición de ser una lengua en trance de desaparecer no es más que una defensa amorosa; así lo explicita con total claridad J. M. Lope Blanch cuando escribe que el judeoespañol (es/está) "guardado amorosamente, cálidamente, por los sefardíes expulsados de España en 1492” (Prólogo de ob. cit. de Marius Sala, cfr. 6). 


\section{BIBLIOGRAFÍA}

\section{Canetti, Elías}

1979 Die gerettete Zunge, Frankfurt am Main, Fischer Taschenbuch Verlag. Traducido al español por Lola Díaz con el titulo La lengua absuelta.

Dalmaroni, Miguel

1993 Juan Gelman. Contra las fabulaciones del mundo, Buenos Aires, Almagesto, "Colección Perfiles".

Darío, Rubén

1986 Prosas Profana y otros poemas (1896-1901), "Palabras liminares", Buenos Aires, Biblioteca Ayacucho, Hyspamérica.

Deleuze/Guattari

1978 Kafka. Por una literatura menor, México, Era.

Gelman, Juan

1994 dibaxu, Buenos Aires, Seix Barral (Biblioteca breve).

Grüner, Eduardo

1988 "La Argentina como pentimento" en: Sitio n 3, Buenos Aires, pp. 71-83. (publicado nuevamente en: Un género culpable. La práctica del ensayo: entredichos, preferencias e intromisiones, Homo Sapiens Ediciones, Rosario, 1996, pp. 31-50.

Hassan, Iacob M.

1970 "Introducción” a Actas del Primer Simposio de Estudios Sefardíes, Instituto "Arias Motao", Madrid. Sala, Marius

1970 Estudios sobre el judeoespañol de Bucarest, México, Universidad Autónoma de México.

Steiner, Georg

1972 Extraterritorial. Ensayos sobre literatura y revolución lingüística. Barcelona, Barral. 